\title{
Hypoglycemic episodes in hospitalized people with diabetes in Portugal: the HIPOS-WARD study
}

Sílvia Alão ${ }^{1^{*}}$ (D) João Conceição ${ }^{2}$, Jorge Dores ${ }^{3}$, Lèlita Santos ${ }^{4,5}$, Francisco Araújo ${ }^{6}$, Estevão Pape ${ }^{7}$, Mónica Reis ${ }^{8}$, Árcia Chipepo ${ }^{6}$, Edite Nascimento ${ }^{9}$, Ana Baptista ${ }^{10}$, Vanessa Pires $^{11}$, Carlos Marques ${ }^{12}$, Adriana De Sousa Lages ${ }^{4}$, João Pelicano-Romano ${ }^{1}$ and Paula M. de Jesus ${ }^{1}$

\begin{abstract}
Background: We intended to estimate the proportion hypoglycemic/hyperglycemic emergency episodes in treated diabetes mellitus (DM) patients admitted to a hospital ward, and calculate the prevalence of risk factors for hypoglycemia and diabetic complications.

Methods: In this cross-sectional, multicentered study, the observational data was collected by physicians from patient's hospitalization to discharge/death. Statistical tests were 2-tailed considering 5\% significance level.

Results: There were 646 ward admissions due to hyperglycemic emergencies and 176 hypoglycemic episodes with a ratio hypoglycemia/hyperglycemia 0.27 for all DM patients. In T2DM patients the ratio was 0.38 . These were mainly female (55.1\%), functionally dependent (61.4\%) and retired/disabled (73.1\%). Median age was 75 years and median duration of disease 11 years. Half the patients were on insulin-based therapy and $30.1 \%$ on secretagoguebased therapy. Approximately $57 \%$ of patients needed occasional/full assistance to manage the disease. The most frequent risk factor for hypoglycemia was polypharmacy (85.0\%). Hypoglycemia in the 12 months before admission was higher in insulin-based therapy patients $(66.1 \% ; p=0.001)$.

Conclusions: Hyperglycemic emergencies are the most frequent cause of hospitalization in Portugal, although severe hypoglycemic events represent a health and social problem in elderly/frail patients. There is still the need to optimize therapy in terms of the potential for hypoglycemia in this patient group and a review of antihyperglycemic agents to add on to insulin.
\end{abstract}

Keywords: Diabetes, Hypoglycemic episodes, Inpatients

\section{Introduction}

Diabetes mellitus (DM) is a chronic disease, characterized by hyperglycemia due to insulin deficiency, insulin resistance, or both $[1,2]$. In Portugal the estimated prevalence of DM among adults (20-79 years) is $13.3 \%$ [3]. The relationship between the burden of hypoglycemia and hyperglycemia has been shifting and evolving $[4,5]$. Achieving

\footnotetext{
* Correspondence: silvia.alao@merck.com

${ }^{1}$ MSD Portugal, R. Qta da Fonte 19, 2770-192 Paço de Arcos, Portugal

Full list of author information is available at the end of the article
}

HbA1c targets $<7 \%(53 \mathrm{mmol} / \mathrm{mol})$ has been shown to reduce microvascular complications of both type 1 and type 2 diabetes when instituted early in the course of disease [6]. International guidelines recommend lowering HbA1c to $<7.0 \%$ in most patients and to keep glycemic control well balanced and managed [7, 8]. However caution is needed in treating diabetes aggressively to near normal HbA1c goals in people with advanced age/frailty, with longstanding type 2 diabetes with or at significant risk of cardiovascular disease. Hypoglycemia is a limiting

(c) The Author(s). 2021 Open Access This article is licensed under a Creative Commons Attribution 4.0 International License, which permits use, sharing, adaptation, distribution and reproduction in any medium or format, as long as you give appropriate credit to the original author(s) and the source, provide a link to the Creative Commons licence, and indicate if changes were made. The images or other third party material in this article are included in the article's Creative Commons licence, unless indicated otherwise in a credit line to the material. If material is not included in the article's Creative Commons licence and your intended use is not permitted by statutory regulation or exceeds the permitted use, you will need to obtain permission directly from the copyright holder. To view a copy of this licence, visit http://creativecommons.org/licenses/by/4.0/ The Creative Commons Public Domain Dedication waiver (http://creativecommons.org/publicdomain/zero/1.0/) applies to the data made available in this article, unless otherwise stated in a credit line to the data. 
factor in achieving glycemic control and often related to poor clinical outcomes in patients with DM, making it difficult to manage [9-11]. Sometimes requiring assistance/hospitalization, hypoglycemia has a significant impact in patients' lives. Typically, hyperglycemia related admissions (diabetes ketoacidosis (DKA), hyperglycemic hyperosmolar non-ketotic syndrome (HHNS)) are the major cause of DM related admissions in non-surgical wards. In the last decade there has been an increasing drive to improve glycemic target achievement with mean HbA1c at the primary care level dropping from $7.8 \%$ in 2010 to $6.8 \%$ in 2015 [3, 12]. While lowering HbA1c might be associated with an increase in the risk of hypoglycemia, Portugal has had a high uptake of innovative anti-hyperglycemic agents associated with lower risk of hypoglycemia (DPP4 inhibitors, SGLT2 inhibitors and GLP1 analogues) and a decrease in the use of sulphonylurea (SU) [3]. It is unclear if this trend impacted diabetes admissions.

Data from HIPOS-ER (HIPOS-Emergency Room) [13, 14] showed that $44.1 \%$ of patients with type 2 diabetes (T2DM) admitted to the emergency room with hypoglycemic episodes due to anti-hyperglycemic therapy were admitted to internal medicine/endocrinology wards, and discharged after 5 days on average. Results confirmed that hypoglycemia places a significant burden both to patient and society, accounting for adverse clinical and financial outcomes. In Portugal there is still a gap in the understanding of hypoglycemia admissions, hypoglycemia risk factors, and how they have evolved since the data from HIPOS-ER increased awareness of the magnitude of the problem.

This observational study aimed to evaluate the ratio of DM patients admitted in the ward due to hypoglycemia episodes vs. hyperglycemic emergencies, to calculate the prevalence of previously described hypoglycemia risk factors and diabetic complications in this population and to characterize patients by treatment group and type of diabetes.

\section{Materials and methods}

The observational, cross-sectional, multicentered HIPOS-WARD (Hypoglycemia In Portugal Observational Study - WARD) study primarily assessed the proportion of hypoglycemic and hyperglycemia emergency episodes in DM treated adult patients that accounted for the admission to an endocrinology/internal medicine ward due to hypoglycemia. The proportion of hypoglycemia/hyperglycemia emergency episodes was also evaluated for T2DM patients.

Patients with diabetes and a hypoglycemic episode were characterized demographically and clinically (type and duration of diabetes, treatment group, diabetes complications, comorbidities, history of hypoglycemia, HbAlc, glycemia, repeated episodes during hospitalization). The prevalence of previously described hypoglycemia risk factors and diabetic complications were also calculated as well as hypoglycemia literacy of patients. Exploratory analyses by treatment group and type of diabetes were performed.

The study population included adult ( $\geq 18$ years old) patients with diabetes treated with a known antihyperglycemic agent, hospitalized in the ward for a hypoglycemia event or as a result of a hypoglycemia episode in the non-hospitalized setting, in one of the 16 participating medical units (18 departments).

Hypoglycemia was defined according to the American Diabetes Association (ADA) $[15,16]$ definition of a modified Whipple's triad (signs and symptoms suggestive of hypoglycemia that resolve with the administration of carbohydrates or glucagon and a glycemia $<70 \mathrm{mg} /$ $\mathrm{dL})$. Diagnosis was made by the attending ER physician, and ward admission was considered if: patients were admitted from the ER due to hypoglycemia; and/or patients that had an episode of hypoglycemia while at the hospital (outpatient clinic/other non-hospitalized setting) were admitted as a direct result of that hypoglycemia. Hospitalization was considered for patients admitted for at least $24 \mathrm{~h}$ for diagnosis/ treatment.

Hospitalized hyperglycemic emergencies included DKA, HHNS and significant hyperglycemia. DKA and HHNS were defined according to ADA's criteria [17]. Significant hyperglycemia was defined as glycemia $\geq 600$ $\mathrm{mg} / \mathrm{dL}$ or clinical symptoms (polyuria, polydipsia). Hyperglycemic emergencies were used to calculate the ratio hypoglycemia/hyperglycemia and not further assessed in this study.

Hypoglycemia literacy was evaluated by a nonvalidated questionnaire created and performed by the investigator to the patient/caregiver (if the patient was unable). Questions focused on the knowledge of the signs and symptoms of hypoglycemia and knowledge of strategies to prevent hypoglycemia.

Treatment subgroups were classified according to the anti-hyperglycemic agent therapy regimen: i) insulin-based therapy (included patients on insulin monotherapy/on insulin with or without other nonsecretagogue drugs); ii) secretagogue-based regimen (included patients on secretagogue monotherapy (sulphonylurea and/or meglitinides), with/without other non-secretagogue drugs); iii) non-secretagoguebased therapy (included patients on drugs that do not include a secretagogue type drug (i.e. metformin, acarbose, glitazones, DPP4 inhibitors, GLP1 receptor agonists, SGLT2 inhibitors)); iv) combination of insulin and secretagogue (included patients that were treated with at least one insulin and one secretagogue type drug (other drugs may have been present)). 
The total study duration was 21 months (November2016-August2018).

All study procedures were performed under standard clinical approach. Observational study data was collected by physicians from hospitalization admission to discharge or death. Data collected included sociodemographic, anthropometrics; diabetes characterization, risk factors; characterization of hypoglycemia episode; hypoglycemia literacy evaluation; laboratory and diagnostic exams; and discharge information.

The study was approved by the Hospital's or local Ethics Committees and by the National Committee for Data Protection. Written informed consent was obtained from all participants.

\section{Statistical methods}

Data were summarized using descriptive statistics (mean, standard deviation, median, minimum and maximum for quantitative variables; counts and percentages for qualitative variables). Missing values were not replaced. Percentages were calculated based on non-missing values.

The ratio of ward admissions due to hypoglycemia per hyperglycemic emergencies was estimated with corresponding 95\% confidence interval (CI). The comparisons of anti-hyperglycemic agent therapy classes or type of diabetes were performed with Chi-square test, Fisher's exact test or Monte Carlo methods (if assumptions were not met) for categorical variables. Quantitative variables were compared using ANOVA or Mann-Whitney test and Kruskal-Wallis test, if assumptions were not met.

Statistical tests were 2-tailed considering 5\% significance level. Statistical analyses were performed using $\mathrm{SAS}^{\circ}$ version 9.4 software (SAS Institute Inc., Cary, NC, USA).

\section{Results}

\section{Ratio hypoglycemia/hyperglycemia}

A total of 646 ward admissions were registered due to hyperglycemic emergencies (328 DKA, 203 HHNS, 115 significant hyperglycemias) in all patients with diabetes. In the same period, there were 176 ward admissions due to hypoglycemia episodes in DM patients. The ratio hypoglycemia/hyperglycemia was $0.27(95 \% \mathrm{CI}=$ $0.23 ; 0.32$ ) for all DM patients. Considering T2DM patients, there were 404 hyperglycemic emergencies and 152 hypoglycemia episodes, in a ratio of $0.38(95 \% \mathrm{CI}=0.31 ; 0.45)$.

\section{Baseline characterization}

The 176 ward admissions due to hypoglycemia episodes are the focus of this analysis. Half the patients included in the study were on insulin-based therapy (50.0\%), $30.1 \%$ were on secretagogue-based therapy, $9.7 \%$ on non-secretagogue therapy and $10.2 \%$ on insulin+secretagogue therapy. The sample was mainly female $(55.1 \%)$ with median age of 75 years and mean body mass index (BMI) $26.0 \mathrm{~kg} / \mathrm{m}^{2}$. A statistically significant association was found between treatment groups and median age $(p=0.009$, insulin+secretagogue and secretagogue patients with higher values) and with $\operatorname{BMI}(p=0.032$, secretagogue-based patients had higher BMI). Approximately $19 \%$ of patients were institutionalized and $23 \%$ of the non-institutionalized were living alone. Most of the patients $(73.1 \%)$ were retired/disabled and only $9.2 \%$ were working full or part time. The hypoglycemia episodes occurred mainly in T2DM patients (86.4\%), with a median duration of disease of 11 years. More than half of patients needed occasional $(27.8 \%)$ or full $(29.5 \%)$ assistance to manage the disease, $61.4 \%$ were functionally dependent. The proportion of patients followed in primary health care was statistically higher $(p<0.001)$ in patients with secretagogue-based therapy (94.3\%), compared to the other groups of treatment. Patients on insulin+secretagogue and insulin-based therapy had a higher median disease duration $(p<0.001)$. Half of the sample suffered from chronic diabetes complications related with the eye (50.0\%: mostly retinopathy), atherosclerotic disease (47.8\%: mostly peripheral artery disease) or nephropathy (47.4\%: mean creatinine: $2.58 \mathrm{mg} / \mathrm{dl}$; mean eGFR: $41.15 \mathrm{ml} / \mathrm{min} / 1.73 \mathrm{~m}^{2}$; mean eGFR basal: 47.60 $\mathrm{ml} / \mathrm{min} / 1.73 \mathrm{~m}^{2}$; mean albumin: $248.42 \mu \mathrm{g} / \mathrm{mg}$; median proteinuria: $344.00 \mathrm{mg}$ ). Presence of eye complications was higher in patients on insulin-based therapy $(62.3 \%$; $p=0.011$ ). Other complications were not statistically different between treatment groups. HbA1c $(p<0.001)$ and the lowest glycemia $(p=0.041)$ in the ward showed statistically significant differences between groups: insulinbased patients had highest median HbA1c (7.6\%) and insulin+secretagogue patients the highest median lowest glycemia $(91.5 \mathrm{mg} / \mathrm{dL})$. Approximately $48 \%$ of the patients had a hypoglycemia in the previous 12 months (mean 2.2 events/patient required assistance from other person; mean 0.5 events/patient pre-hospital assistance; mean 0.7 events/patient ER assistance). From those, $70.4 \%$ had hypoglycemia in the previous 30 days. One episode occurred while the patient was driving. The proportion of patients with hypoglycemia in the 12 months previous to admission was higher in patients on insulinbased therapy $(66.1 \%)$ with statistically significant differences $(p=0.001)$ (Table 1).

\section{Hypoglycemia episode characterization}

The most frequent triggering causes of hypoglycemia were carbohydrate deficit (including 'missed or delayed meal' and 'meal inappropriately low in carbohydrates') (54.0\%), acute illness $(40.2 \%)$ and related to insulin therapy $(34.3 \%)$. As determined by the investigators, approximately $15 \%$ of patients had associated complications as a result of hypoglycemia, most frequently neurologic and 
Table 1 Baseline patient's characteristics, overall and by class of anti-hyperglycemic agent

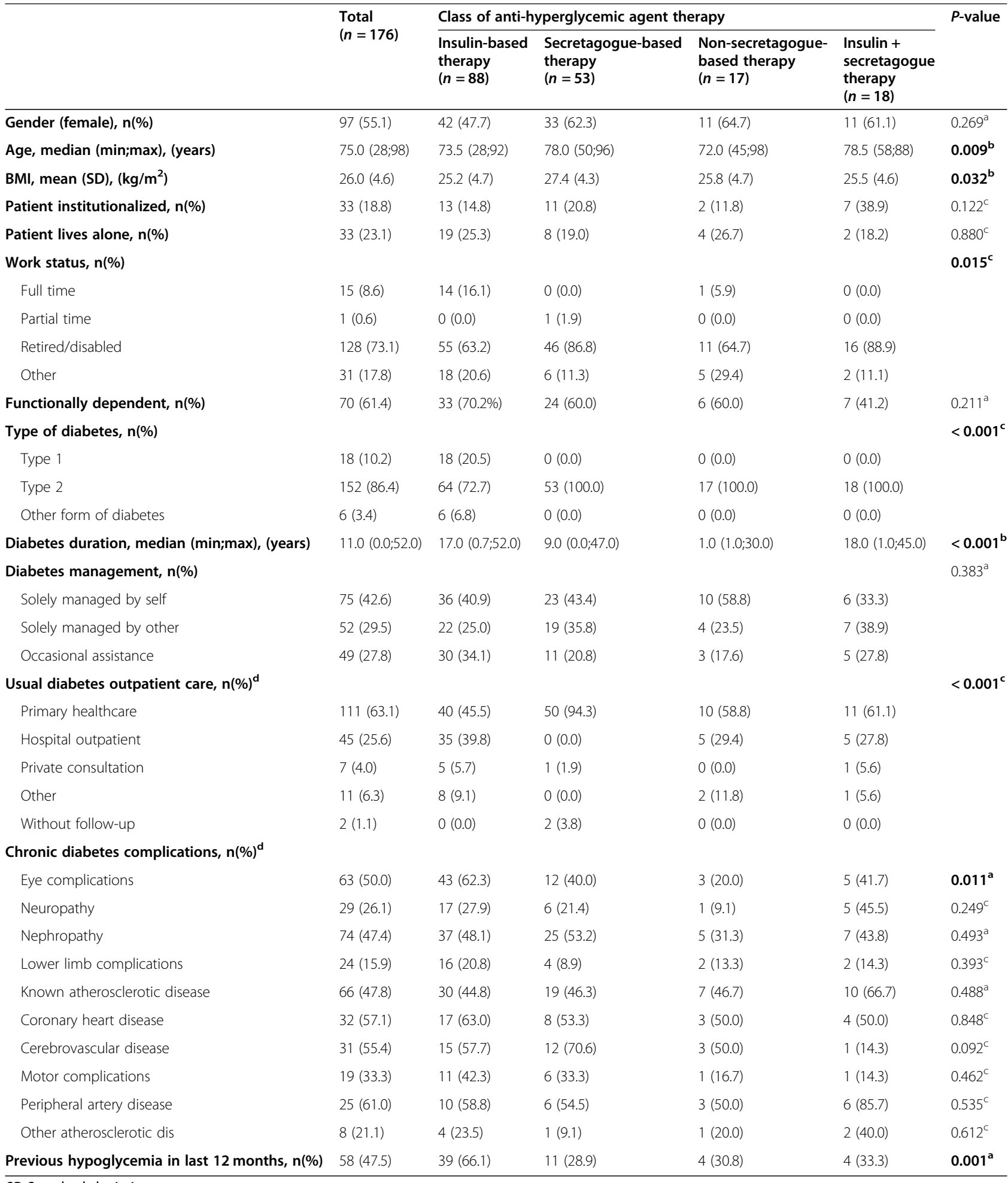

SD Standard deviation

${ }^{a}$ Chi-square test; ${ }^{b}$ Kruskal-Wallis test; ${ }^{c}$ Monte Carlo methods; ${ }^{\text {d }}$ Each patient can have more than one

infectious complications (3 aspiration pneumonias, 2 lower urinary tract infections, 1 pyelonephritis, 1 sepsis and 1 conjunctivitis).
The median lowest glycemia recorded at ER admission or pre-hospital was $40.0 \mathrm{mg} / \mathrm{dL}(9.0-298.0 \mathrm{mg} / \mathrm{dL})$ and $74.0 \mathrm{mg} / \mathrm{dL}(20.0-268.0 \mathrm{mg} / \mathrm{dL})$ in the ward. A total of 
63 patients (36.0\%) had a repeated hypoglycemia during hospitalization, none of which led to further complications. The relative frequency of patients with hypoglycemia during the hospitalization was $47.1 \%$ on insulin-based patients, $26.4 \%$ on secretagogue-based patients, $29.4 \%$ on non-secretagogue and $16.7 \%$ on insulin+secretagogue patients $(p=0.018)$. There were no statistical differences in the length of stay or hospitalization outcome, however there were more deaths in the insulin-based patients.

The risk factors for hypoglycemia and the risk factors for complications following an event were also assessed. The most frequent risk factor was polypharmacy $(>5$ distinct drugs), in $85.0 \%$ of patients, followed by age > 75 years $(49.4 \%)$. Age $>75$ years was statistically different between treatment groups with $72.2 \%$ patients from insulin+secretagogue and $35.3 \%$ patients from nonsecretagogue regimen $(p=0.017)$. Heart failure was the most frequently reported (28.9\%) risk factor for complications after an event (Table 2).

The median time spent by patients in the ER was approximately $9.1 \mathrm{~h}$ and $146.6 \mathrm{~h} / 6.1$ days in the ward. Approximately $64 \%$ of patients were discharged back home, while $17.6 \%$ went to an institution/another hospital and 4.5\% (8 patients) died (Table 2). About 43\% of the patients were referred to hospital diabetes/endocrinology outpatient clinic and $32.9 \%$ to the general practitioner.

\section{Hypoglycemia literacy}

Patients were evaluated on their knowledge of identifying, treating and preventing a hypoglycemia event (hypoglycemia literacy questionnaire). The questionnaire was answered by $77.1 \%(n=135)$ of patients and $22.9 \%$ $(n=40)$ of caregivers. Approximately $75 \%(n=132)$ of the patients knew 'what is a hypoglycemia, 'hypo' or 'a drop in blood sugar'. From these, $90.9 \%(n=120)$ knew 'how to identify it', $84.8 \%(n=112)$ knew 'what to do in case of hypoglycemia' $(98.2 \%(n=110)$ answered 'ingest a form of simple carbohydrate') and $63.6 \%(n=84)$ knew 'what to do to prevent it'.

\section{Subgroup analyses by type of diabetes}

In the study population, $86.4 \%$ of patients had T2DM, $10.2 \%$ T1DM and $3.4 \%$ had another form of diabetes (3 patients 'post pancreatectomy', 1 patient 'after surgery', 1 patient 'secondary' and 1 patient 'secondary to pancreatitis'). Due to its small size, the group 'other type of diabetes' was excluded from the inferential analysis. Characterization by type of diabetes is described on Table 3.

Among T1DM patients, higher statistical differences between groups were found for disease duration (median 22.0 vs 10.0 years), diabetes management by self $(72.2 \%$ vs $38.2 \%)$, eye and neuropathy complications ( $81.3 \%$ vs $46.2 \%$; $50.0 \%$ vs $20.9 \%$ ), and hypoglycemia in the last 12 months ( $85.7 \%$ vs $40.4 \%)$.

For T2DM patients statistically significant differences were found for age (78.0 vs 49.5), BMI ( $26.3 \mathrm{vs} 22.9 \mathrm{~kg} / \mathrm{m}^{2}$ ), primary healthcare follow-up (68.4\% vs $22.2 \%)$, atherosclerotic disease complication (51.7\% vs $14.3 \%$ ), and polypharmacy as risk factor ( $90.0 \%$ vs $41.2 \%)$.

\section{Discussion}

In the HIPOS-WARD study we evaluated patients with diabetes and a hypoglycemic episode that caused a hospitalization, focusing on the clinical characterization.

The hypoglycemia/hyperglycemia ratio was 0.27 for all DM patients and 0.38 in T2DM patients. For each hypoglycemia episode, there were approximately 4 hyperglycemic emergencies for all DM patients, and 3 for T2DM patients. These results were not as expected, and might be explained due to the safer and more effective state of hypoglycemia drugs, which lead to its decreasing occurrence. Additionally, the burden of hypoglycemia in inpatients in Portugal appears to be relevant but lower than the burden of hyperglycemia both in T1DM and T2DM. As no longitudinal data is available it is unknow how the situation has evolved over recent years. Lipska et al. [5] described between 1999 and 2011 in the USA a steady increase of admissions due to hypoglycemia, eventually overtaking admissions due to hyperglycemia in the first decade of this century. However, this was before therapies with a lower potential of hypoglycemia (DPP4i, SGLT2i and GLP1 analogues) were introduced or widely used [18, 19]. It is unknown if wider use of these agents, as well as decreasing use of SU type drugs and growing awareness of the risk of hypoglycemia reversed the trend once more. More recent insulin formulations are also associated with lower rates of hypoglycemia in T1DM and in some settings for T2DM [20-22]. In Portugal the use of antihyperglycemic agents with a low risk of hypoglycemiaDPP4i in particular-has increased substantially since early in the twenty-first century representing $25 \%$ of all oral drugs in 2015, while SU's dropped from 54\% in 2000 to $20 \%$ in 2015 [3]. Furthermore, increased awareness of hypoglycemia conveyed by national and international guidelines $[21,23]$ as well as the national studies HIPOS-ER [13], on severe hypoglycemia and HIPOS-PHARMA [24], a pharmacy level evaluation of mild/moderate hypoglycemia, might have contributed to a blunting in the rates of hypoglycemia. Also, glycemic target achievement in the National Health System (NHS) primary care has improved between 2010 and 2015 [3, 12]. This, overall, might suggest the importance of anti-hyperglycemic agent with a lower risk of 
Table 2 Hypoglycemia episode characterization, overall and by class of anti-hyperglycemic agent

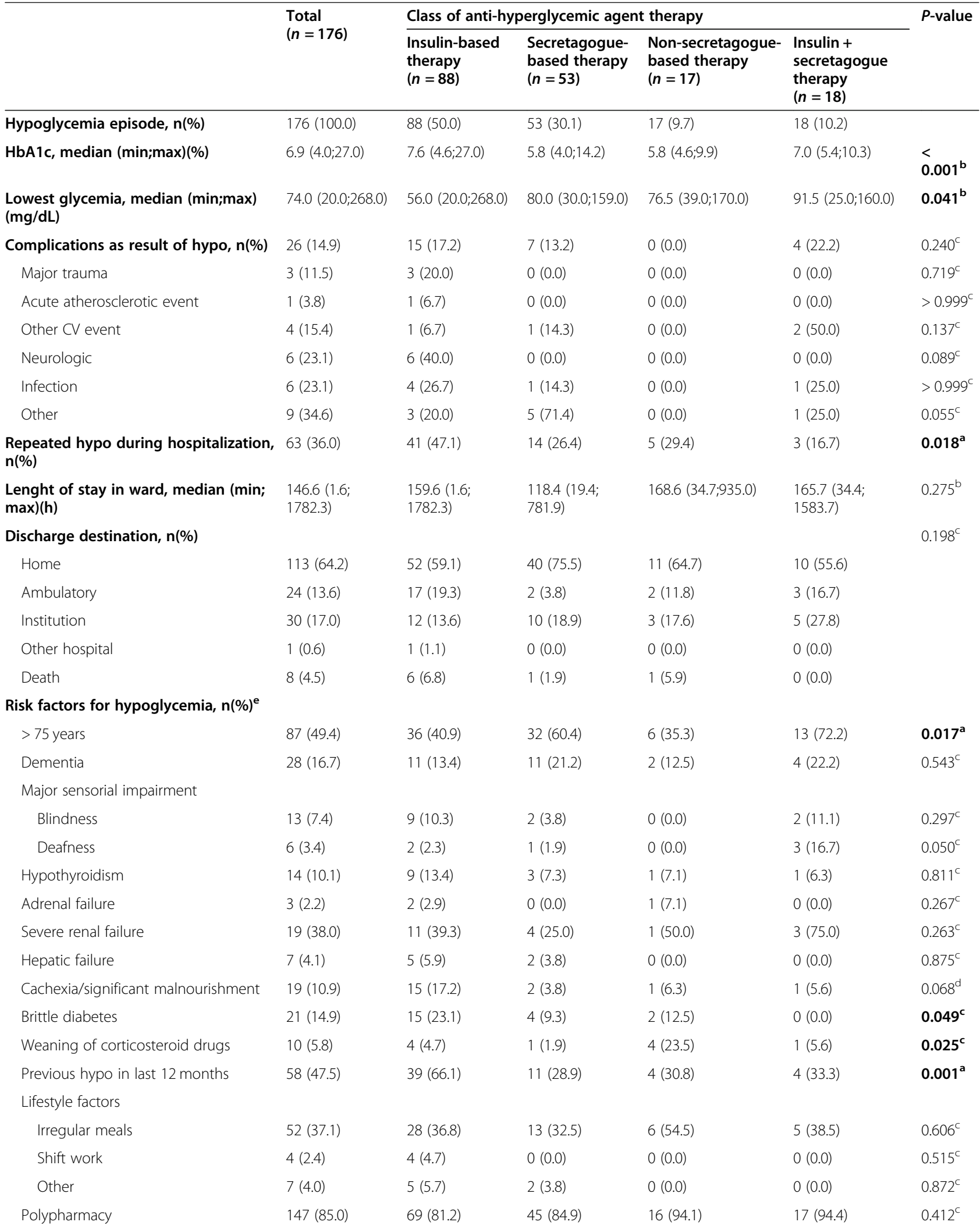


Table 2 Hypoglycemia episode characterization, overall and by class of anti-hyperglycemic agent (Continued)

\begin{tabular}{|c|c|c|c|c|c|c|}
\hline & \multirow{2}{*}{$\begin{array}{l}\text { Total } \\
(n=176)\end{array}$} & \multicolumn{4}{|c|}{ Class of anti-hyperglycemic agent therapy } & \multirow[t]{2}{*}{$P$-value } \\
\hline & & $\begin{array}{l}\text { Insulin-based } \\
\text { therapy } \\
(n=88)\end{array}$ & $\begin{array}{l}\text { Secretagogue- } \\
\text { based therapy } \\
(n=53)\end{array}$ & $\begin{array}{l}\text { Non-secretagogue- } \\
\text { based therapy } \\
(n=17)\end{array}$ & $\begin{array}{l}\text { Insulin }+ \\
\text { secretagogue } \\
\text { therapy } \\
(n=18)\end{array}$ & \\
\hline \multicolumn{7}{|c|}{ High risk for complications after the event } \\
\hline Coronary heart disease & $32(25.0)$ & 17 (26.6) & $8(21.6)$ & $3(21.4)$ & $4(30.8)$ & $0.897^{c}$ \\
\hline Cerebrovascular disease & $31(24.2)$ & $15(23.8)$ & $12(30.8)$ & $3(21.4)$ & $1(8.3)$ & $0.613^{c}$ \\
\hline Heart failure & $48(28.9)$ & $20(23.8)$ & $19(36.5)$ & $3(23.1)$ & $6(35.3)$ & $0.372^{d}$ \\
\hline Peripheral artery disease & $25(22.1)$ & $10(18.5)$ & $6(18.2)$ & $3(21.4)$ & $6(50.0)$ & $0.151^{c}$ \\
\hline Osteoporosis & $8(7.6)$ & $3(5.4)$ & $3(10.0)$ & $1(9.1)$ & $1(12.5)$ & $0.518^{c}$ \\
\hline Living alone & 33 (18.8) & 19 (21.6) & $8(15.1)$ & $4(23.5)$ & $2(11.1)$ & $0.642^{c}$ \\
\hline
\end{tabular}

${ }^{a}$ Chi-square test; ${ }^{b}$ Kruskal-Wallis test; ${ }^{c}$ Monte Carlo methods; ${ }^{d}$ Fisher's exact test; ${ }^{e}$ Each patient can have more than one; Polyphramacy: $>5$ distinct drugs, for one or more conditions

hypoglycemia in containing the risk of severe hypoglycemia.

HIPOS-WARD only focused on the most severe hypoglycemia occurrences that lead to hospitalization and identified its clinical and economic burden [25] but does not cover the entire scope of the hypoglycemia problem.

Unfortunately, the lack of longitudinal data in Portugal cannot exclude the possibility-although unlikely-that the rate of hypoglycemia is still increasing. Irrespective of the causes our data reinforces the importance of anti-hyperglycemic agent with a low risk of hypoglycemia either as a contributing factor to curb it's putative increase or to limit a future increase.

HIPOS-WARD reinforces the relevance of these therapies: the occurrence of hypoglycemic episodes was higher in patients on an insulin-based therapy followed by those on a secretagogue-based therapy, which are indeed associated to additional side effects and an increased risk of hypoglycemia [26-28]. Insulin+secretagogue therapy accounted for $10.2 \%$ of the sample and $9.7 \%$ were on non-secretagogue regimen. Therapeutic regimens based on or including secretagogues were more common in elderly patients and those followed in primary healthcare, which might be associated to treatment cost restrictions or related to clinical inertia. Drug prescription is indifferently managed by specialists/GPs and new antidiabetic drugs can be freely prescribed by all physicians. Although these patients are mostly seen at a primary care setting they are usually evaluated by in-hospital consultation when they fail to achieve control and need to add injectable therapy-like insulin-to their care or when they show complications from the disease. Our findings have shown that the insulin+secretagogue based therapy group was statistically associated with risk factors including disease duration and age, having higher proportion of patients with coronary heart disease, peripheral artery disease and osteoporosis. Also, a large group of patients reported nephropathy, a conventional risk factor for hypoglycemia in people with diabetes, due to multiple factors as the decrease of insulin clearance and it's degradation in peripheral tissues, reduction in glycogen stores, reduced renal gluconeogenesis [29-31]. Also, commonly used antidiabetic drugs are renally excreted and have a prolonged half-life in patients with CKD, predisposing them to episodes of hypoglycemia. The confluence of these factors may contribute to a greater risk for hypoglycemia among patients with CKD and may be an unintended consequence of therapy to treat hyperglycemia in these patients [32]. Patients on secretagogue-based therapy had a higher proportion of cerebrovascular disease and heart failure. Again, this denotes the frailty of patients at higher risk of hypoglycemia and the importance of adopting strategies and therapies that minimize its risk [33, 34]. The actual increasing number of new AHAs with an intrinsic low risk of hypoglycemia are an important therapeutic option, however, patients and caregivers education are also crucial $[35,36]$.

This study also included T1DM patients, representing the first Portuguese national dataset on this population. Patients with T1DM, due to intensive insulin therapy, are usually associated with a higher risk of hypoglycemia [10] and in our study $85.7 \%$ of T1DM vs only $40.4 \%$ of T2DM had a hypoglycemic episode in previous 12 months. However, during the study period only $10.2 \%$ of the total hypoglycemia admissions were in T1DM and so hypoglycemia in T2DM represented the biggest burden of hypoglycemia events requiring hospitalization, highlighting that hypoglycemia is a very relevant issue in T2DM. It is well known that hypoglycemia triggered by secretagogues can be long-lasting, more severe and recurrent. Although expected, this data also shows that T1DM have a higher burden of microvascular complications whereas T2DM more atherosclerotic complications. This data alert to the importance of a patient 
Table $\mathbf{3}$ Characterization by type of diabetes

\begin{tabular}{|c|c|c|c|c|}
\hline & Total & Type of diabet & & $P$-value \\
\hline & & $\begin{array}{l}\text { Type } 1 \\
(n=18)\end{array}$ & $\begin{array}{l}\text { Type } 2 \\
(n=152)\end{array}$ & \\
\hline Hypoglycemia episode, n(\%) & $176(100.0)$ & $18(10.2)$ & $152(86.4)$ & \\
\hline Gender (female), n(\%) & $97(55.1)$ & $6(33.3)$ & $88(57.9)$ & $0.048^{\mathrm{a}}$ \\
\hline Age, median (min;max), (years) & $75.0(28 ; 98)$ & $49.5(28.0 ; 74.0)$ & $78.0(35.0 ; 98.0)$ & $<0.001^{\mathrm{b}}$ \\
\hline BMI, median (min;max), $\left(\mathrm{kg} / \mathrm{m}^{2}\right)$ & $26.0(4.6)$ & $22.9(18.4 ; 31.6)$ & $26.3(15.6 ; 38.8)$ & $0.009^{d}$ \\
\hline Diabetes duration, median (min;max), (years) & $11.0(0.0 ; 52.0)$ & $22.0(4.0 ; 52.0)$ & $10.0(0.0 ; 51.0)$ & $0.001^{\mathrm{b}}$ \\
\hline Diabetes management, $\mathrm{n}(\%)$ & & & & $0.013^{\mathrm{a}}$ \\
\hline Solely managed by self & $75(42.6)$ & $13(72.2)$ & $58(38.2)$ & \\
\hline Solely managed by other & $52(29.5)$ & $1(5.6)$ & $50(32.9)$ & \\
\hline Occasional assistance & $49(27.8)$ & $4(22.2)$ & $44(28.9)$ & \\
\hline Usual diabetes outpatient care, $n(\%)^{f}$ & & & & $0.001^{c}$ \\
\hline Primary health care & $111(63.1)$ & $4(22.2)$ & $104(68.4)$ & \\
\hline Hospital outpatient & $45(25.6)$ & $11(61.1)$ & $31(20.4)$ & \\
\hline Private consultation & $7(4.0)$ & $1(5.6)$ & $6(3.9)$ & \\
\hline Other & $11(6.3)$ & $2(11.1)$ & $9(5.9)$ & \\
\hline Without follow-up & $2(1.1)$ & $0(0.0)$ & $2(1.3)$ & \\
\hline Chronic diabetes complications, $n(\%)^{f}$ & & & & \\
\hline Eye complications & $63(50.0)$ & $13(81.3)$ & $48(46.2)$ & $0.014^{\mathrm{e}}$ \\
\hline Neuropathy & $29(26.1)$ & $7(50.0)$ & $19(20.9)$ & $0.040^{\mathrm{e}}$ \\
\hline Nephropathy & $74(47.4)$ & $6(37.5)$ & $67(49.6)$ & $0.359^{a}$ \\
\hline Lower limb complications & $24(15.9)$ & $2(11.8)$ & $20(15.6)$ & $>0.999^{e}$ \\
\hline Known atherosclerotic disease & $66(47.8)$ & $2(14.3)$ & $62(51.7)$ & $0.008^{\mathrm{a}}$ \\
\hline Coronary heart disease & $32(57.1)$ & $2(100.0)$ & $29(55.8)$ & \\
\hline Cerebrovascular disease & $31(55.4)$ & $1(100.0)$ & $30(56.6)$ & \\
\hline Motor complications & $19(33.3)$ & $0(0.0)$ & $19(35.8)$ & \\
\hline Peripheral artery disease & $25(61.0)$ & $1(100.0)$ & $24(63.2)$ & \\
\hline Other atherosclerotic dis & $8(21.1)$ & $0(0.0)$ & $7(20.0)$ & \\
\hline Previous hypoglycemia in last 12 months, $\mathrm{n}(\%)$ & $58(47.5)$ & $12(85.7 \%)$ & $42(40.4 \%)$ & $0.001^{\mathrm{a}}$ \\
\hline Repeated hypo during hospitalization, $n(\%)$ & $63(36.0)$ & $7(41.2 \%)$ & $51(33.6 \%)$ & $0.530^{\mathrm{a}}$ \\
\hline Length of stay in ward, median (min;max)(h) & $146.6(1.6 ; 1782.3)$ & & & \\
\hline Discharge destination, $\mathrm{n}(\%)$ & & & & $0.052^{c}$ \\
\hline Home & $113(64.2)$ & $13(72.2)$ & $98(64.5)$ & \\
\hline Ambulatory & $24(13.6)$ & $5(27.8)$ & $16(10.5)$ & \\
\hline Institution & $30(17.0)$ & $0(0.0)$ & $29(19.1)$ & \\
\hline Other hospital & $1(0.6)$ & $0(0.0)$ & $1(0.7)$ & \\
\hline Death & $8(4.5)$ & $0(0.0)$ & $8(5.3)$ & \\
\hline Risk factors for hypoglycemia, $n(\%)^{f}$ & & & & \\
\hline$>75$ years & $87(49.4)$ & $0(0.0)$ & $86(56.6)$ & $<0.001^{a}$ \\
\hline Dementia & $28(16.7)$ & $0(0.0)$ & $28(19.0)$ & $0.081^{e}$ \\
\hline Major sensorial impairment & & & & \\
\hline Blindness & $13(7.4)$ & $4(23.5)$ & $8(5.3)$ & $0.021^{e}$ \\
\hline Deafness & $6(3.4)$ & $1(5.9)$ & $5(3.3)$ & $0.476^{\mathrm{e}}$ \\
\hline Hypothyroidism & $14(10.1)$ & $3(18.8)$ & $11(9.4)$ & $0.376^{e}$ \\
\hline
\end{tabular}


Table $\mathbf{3}$ Characterization by type of diabetes (Continued)

\begin{tabular}{|c|c|c|c|c|}
\hline & \multirow{2}{*}{$\begin{array}{l}\text { Total } \\
(n=176)\end{array}$} & \multicolumn{2}{|c|}{ Type of diabetes } & \multirow[t]{2}{*}{$P$-value } \\
\hline & & $\begin{array}{l}\text { Type } 1 \\
(n=18)\end{array}$ & $\begin{array}{l}\text { Type } 2 \\
(n=152)\end{array}$ & \\
\hline Adrenal failure & $3(2.2)$ & $1(7.1)$ & $2(1.7)$ & $0.288^{\mathrm{e}}$ \\
\hline Severe renal failure & $19(38.0)$ & $2(40.0)$ & 17 (38.6) & NA \\
\hline Hepatic failure & $7(4.1)$ & $0(0.0)$ & $7(4.7)$ & $>0.999^{e}$ \\
\hline Cachexia/significant malnourishment & 19 (10.9) & $3(17.6)$ & $12(7.9)$ & $0.181^{\mathrm{e}}$ \\
\hline Brittle diabetes & $21(14.9)$ & $6(46.2)$ & $13(10.5)$ & $0.003^{\mathrm{e}}$ \\
\hline Weaning of corticosteroid drugs & $10(5.8)$ & $1(5.9)$ & $9(6.0)$ & $>0.999^{e}$ \\
\hline Previous hypo in the last 12 months & $58(47.5)$ & $12(85.7)$ & $42(40.4)$ & $0.001^{\mathrm{a}}$ \\
\hline \multicolumn{5}{|l|}{ Lifestyle factors } \\
\hline Irregular meals & $52(37.1)$ & $8(50.0)$ & $41(34.7)$ & $0.235^{\mathrm{a}}$ \\
\hline Shift work & $4(2.4)$ & $3(18.8)$ & $1(0.7)$ & $0.003^{e}$ \\
\hline Other & $7(4.0)$ & $1(5.9)$ & $5(3.3)$ & $0.478^{e}$ \\
\hline Polypharmacy & $147(85.0)$ & $7(41.2)$ & $135(90.0)$ & $<0.001^{\mathrm{e}}$ \\
\hline \multicolumn{5}{|c|}{ High risk for complications after the event } \\
\hline Coronary heart disease & $32(25.0)$ & $2(14.3)$ & $29(26.4)$ & $0.514^{e}$ \\
\hline Cerebrovascular disease & $31(24.2)$ & $1(7.7)$ & $30(27.0)$ & $0.182^{e}$ \\
\hline Heart failure & $48(28.9)$ & $0(0.0)$ & 48 (33.6) & $0.004^{\mathrm{a}}$ \\
\hline Peripheral artery disease & $25(22.1)$ & $1(7.7)$ & $24(25.0)$ & $0.291^{e}$ \\
\hline Osteoporosis & $8(7.6)$ & $1(6.7)$ & $7(8.1)$ & $>0.999^{e}$ \\
\hline Living alone & $33(18.8)$ & $9(50.0)$ & $22(14.5)$ & $0.001^{\mathrm{e}}$ \\
\hline
\end{tabular}

${ }^{a}$ Chi-square test; ${ }^{b}$ Kruskal-Wallis test; ${ }^{c}$ Monte Carlo approach; ${ }^{d}$ ANOVA; ${ }^{e}$ Fisher's exact test; ${ }^{f}$ Each patient can have more than one; Polyphramacy: $>5$ distinct drugs, for one or more conditions

centered approach to choosing appropriate pharmacologic treatment of blood glucose, including important comorbidities such as atherosclerotic cardiovascular disease. The rates of microvascular complications in T2DM ranged between 20.9-46.2\% underscoring the importance of glycemic control on both groups in order to prevent these complications with great impact in quality of life [37-39].

Elderly, functionally dependent individuals (frail/nonfrail) are exposed [40] and identified to have higher risk of hypoglycemia [10, 16, 33, 41-44]. Therefore, these patients should be cared for in a different way to mitigate the risk of this and other adverse events. Our results are consistent with a ward admitted patient population having T2DM, predominantly elderly, frail, with multiple comorbidities and moderately dependent, mainly treated with insulin and secretagogues. These hospitalizations were frequently preceded by similar and recent episodes, which reinforces the idea that these patients usually present recurrent hypoglycemia episodes, increasing the risk to develop complications at each occurrence. Moreover, more than half of patients need help (total/partial) to manage their diabetes treatment, denoting the frailty of these individuals at high risk of inadequate use of drugs and consequently at risk of having more severe episodes related to uncontrolled glycemia. The main risk factors for a hypoglycemia event were polypharmacy ( $>5$ distinct drugs, for one or more conditions) $[45,46]$ and age $>75$ years, and heart failure was the most frequent risk factor for complications after an event.

Results are consistent with HIPOS-ER study [13], which triggered HIPOS-WARD by showing that, in a setting of ER, more than $40 \%$ of T2DM patients with severe hypoglycemia had been hospitalized as consequence of the event.

Overall, our data suggests that while hyperglycemia is still the major cause of hospital admissions for both types of diabetes, over $60 \%$ of all hypoglycemia admissions happened in patients with functional impairment and, in T2DM, elderly patients. This underscores that there is still work to be done in terms of avoiding clinical inertia and recurrence of hypoglycemic events in this patient group, questioning the use of secretagogue-based therapy and some combinations like $\mathrm{SU}+$ insulin, reinforcing the importance to increase the number of anti-hyperglycemic agents with low risk of hypoglycemia as a therapeutic option [35, 36] and developing educational and/or support programs for patients/caregivers, especially designed 
for populations at higher risk, in order to minimize the risk for complications.

Overall, the most likely causes of hypoglycemia were due to carbohydrate deficit, by a cause secondary to acute illness or related to insulin therapy. These potential causative factors should be addressed by systematically discussing it with all patients who are at increased risk of hypoglycemia as well as with their caregivers. For three quarters of patients hypoglycemia was the main driver for ward admission and the most frequent complications as result of the hypoglycemia episode that triggered the admission were neurologic and infection. This might indicate the Portuguese NHS approach by both specialists and primary care providers might have curbed the rates of hypoglycemia despite improving in diabetes target achievement. The growing use of new antihyperglycemic drug classes which have an intrinsic lower risk of hypoglycemia might be contributing to a decrease in the prevalence of severe hypoglycemia.

This study was not randomized or controlled, therefore results are primarily descriptive. Its observational nature may be considered a limitation and since no individual drug level information has been collected (only anti-hyperglycemic agent therapy group as predetermined), it was not possible to determine specific causal associations. In order to minimize selection bias, patients were enrolled in a consecutive manner, in different centers throughout the country, which gives a wider overview of the information collected $[41,42]$. However, there was clearly a higher number of T2DM patients and a low number of patients on non-secretagogue and insulin+secretagogue therapies in this study.

As a strength of the study we point out the specific tools (study questionnaire and literacy questionnaire) designed to adequately capture the information in accordance with its cross-sectional nature [44, 47]. Also, this study was part of an integrated series designed to evaluate adult patients with diabetes in pharmaciesHIPOS-PHARMA [24], in the emergency room-HIPOSER [13, 14], and hospitalized-HIPOS-WARD, contributing to a full country perspective.

In conclusion, in this study hyperglycemic emergencies were more frequent while the lack of longitudinal data doesn't allow for trend projection. Elderly T2DM patients with functional impairment represent the bulk of admissions for hypoglycemia, highlighting there is still the need to optimize therapy in terms of the potential for hypoglycemia in this patient group, balancing glycemic target achievement with hypoglycemia avoidance. The study confirms higher rates of hypoglycemia in T1DM, highlighting the critical problem this complication represents, the overwhelming contribution of T2DM to the total burden, and the importance of this complication for both patients and the National Health System. Future efforts should also be taken to better characterize and prevent hyperglycemic occurrences especially in T2DM patients.

\section{Acknowledgments}

The authors wish to acknowledge the contribution of the following investigators: Vanessa Pires, Ana Filipa Rebelo, Ana Costa, Andreia Costa, Anusca Paixão, Helena Santos Gonçalves, Joana Almeida Calvão, Mónica Dinis de Mesquita, Nélson Jorge, Paulo Subtil, Rita Carneiro Silva [Centro Hospitalar de Trás-os-Montes e Alto Douro]; Mónica Reis, Denise da Cruz, Diana Falcão, Luísa Teixeira, Nuno Sousa, Zara Soares [Hospital de Vila Franca de Xira]; Carlos Marques, Ana Grilo, Filipa Lage, Isabel Ramoa, Patrícia Marujo, Pedro Fortes, Rosa Mendes, Vera Cesário, Vera Guerreiro [Unidade Local de Saúde do Baixo Alentejo]; Estevão Pape, Andreia Nunes, Conceição Escarigo, Rita Nortadas, Sara Ramalho [Hospital Garcia de Orta]; João Correia, Alexandre Fontoura, Hugo Almeida, Pedro Vieira, Rita Fernandes, Sónia Canadas [Unidade Local de Saúde da Guarda]; Paula Freitas, Cesar Esteves, Daniela Salazar, Jorge Pedro, Maria Joao Ferreira, Vanessa Guerreiro [Centro Hospitalar de São João]; Arcia Chipepo, Alexei Bucur, Ana Gonçalves, Sofia Mateus, Steeve Rosado, Vanda Jorge, Vasco Evangelista, Yasmin Mamade [Hospital Beatriz Ângelo]; Edite Nascimento, Filipa Mendonça, Joana Lemos, Mafalda Miranda, Miguel Sequeira, Mónica Teixeira, Nuno Monteiro, Rui Marques [Centro Hospitalar Tondela Viseu]; Rogério Vicente Ferreira, Diana Oliveira, Diogo Conceição, José Mateus, Patrícia Mendes, Sara Sintra [Centro Hospitalar Universitário de Coimbra]; Diana Guerra, Alexandra Esteves, António Ferreira, Duarte Silva, Fernando Correia, Francisco Silva, Joana Couto, João Pedro Pais, José Costa Carvalho, Lúcia Brandão, Miguel Romano, Pedro Pinto, Raquel Afonso, Rosana Maia, Soraia Azevedo [Unidade de Saúde Local do Alto Minho]; Ana Batista, Ana Isabel Rodrigues, Ana Rita Clara, Cristina Sousa, Luís Vicente, Mariana Figueiras, Micael Mendes, Sérgio Pina, Sofia Amálio, Teresa Salero [Centro Hospitalar Universitário do Algarve - Faro]; Estela Ferrão, Marta Duarte, Nádia Fernandes, Nina Fernandes [Centro Hospitalar Universitário do Algarve - Portimão]; Isabel Paiva, Adriana Lages, Nélson Cunha [Centro Hospitalar e Universitário de Coimbra]; João Madeira Lopes, Cristiana Mendes, Dúlio Teixeira Passos, Filipe Bessa, Francisco Cunha, Frederico Trigueiros, Inês Machado Leite, Liliana Santos, Nina Salvado [Centro Hospitalar Lisboa Norte]; André Carvalho, Ana Amado, Arlindo Guimas [Centro Hospitalar Universitário do Porto]; Teresa Sequeira, Ana Vigário, Sara Raquel Martins, Tânia Ferreira [Centro Hospitalar Universitário do Porto]; João Sequeira Duarte, Ana Sofia Carvalho, Carlos Tavares Bello, Carlos Vasconcelos, Catarina Saraiva, Cátia Ferrinho, Dora Xete, Ricardo Capitão [Centro Hospitalar Lisboa Ocidental]; Ilídio Brandão, Ana Rita Marques, Carlos Capela, Isabel Eira, Luísa Pinto, Mariana Barbosa, Rita Magalhães, Rosana Magalhães, Sandra Correia [Hospital de Braga].

Medical writing and editorial assistance were provided by Catarina Alves, Medical Writer at Eurotrials, Scientific Consultants (now part of CTI Clinical Trial \& Consulting Services), funded by MSD Portugal. Statistical support was provided by Vera Vicente, Senior Statistician at Eurotrials, Scientific Consultants (now part of CTI Clinical Trial \& Consulting Services) and funded by MSD Portugal.

\section{Authors' contributions}

Sílvia Alão contributed to conceptualization, methodology, project administration, validation, and review of final version. João Conceição contributed to conceptualization, methodology, project administration, investigation, validation, original draft and review/editing of final version. Jorge Dores contributed to conceptualization, methodology, data curation, validation, original draft and review/editing of final version. Lèlita Santos contributed to conceptualization, methodology, data curation, validation, original draft and review/editing of final version. Francisco Araújo contributed to conceptualization, methodology, data curation, validation, original draft and review/editing of final version. Estevão Pape contributed to data curation and review of final version. Mónica Reis contributed to data curation and review of final version. Árcia Chipepo contributed to data curation and review of final version. Edite Nascimento contributed to data curation and review of final version. Ana Baptista contributed to data curation and review of final version. Vanessa Pires contributed to data 
curation and review of final version. Carlos Marques contributed to data curation and review of final version. Adriana De Sousa Lages contributed to data curation and review of final version. João Pelicano-Romano contributed to investigation, validation, original draft and review/editing of final version. Paula M de Jesus contributed to project administration. The author(s) read and approved the final manuscript.

\section{Funding}

This work was supported by Merck Sharp \& Dohme (MSD) Portugal [MK0431-854]. The study was scientifically promoted by the Portuguese Society of Diabetology (Sociedade Portuguesa de Diabetologia), Portuguese Society of Endocrinology, Diabetes and Metabolism (Sociedade Portuguesa de Endocrinologia, Diabetes e Metabolismo) and Portuguese Society of Internal Medicine (Sociedade Portuguesa de Medicina Interna).

\section{Availability of data and materials}

Merck Sharp \& Dohme Corp., a subsidiary of Merck \& Co., Inc., Kenilworth, NJ, USA's data sharing policy, including restrictions, is available at http://engagezone.msd.com/ds_documentation.php. Requests for access to the clinical study data can be submitted through the EngageZone site or via email to dataaccess@merck.com.

\section{Ethics approval and consent to participate}

The study was approved by the Hospital's or local Ethics Committees and by the National Committee for Data Protection.

\section{Consent for publication}

Not applicable.

\section{Competing interests}

Sílvia Alão is an employee of MSD Portugal.

Lèlita Santos has served as a paid lecturer and/or a consultant to Merck Sharp \& Dohme, Lda, Portugal, and Astra-Zeneca Portugal. Jorge Dores has served as a paid lecturer and/or a consultant to Merck Sharp \& Dohme, Lda, Portugal, Abbott Diagnostics, Portugal, Astra-Zeneca Portugal, Boehringer-Ingelheim, Portugal, Lilly Produtos Farmacêuticos, Portugal, Novartis Farma, Novo-Nordisk Portugal and Sanofi, Portugal. Francisco Araújo has served as a paid lecturer and/or research grant to Merck Sharp \& Dohme, Lda, Portugal, Astra-Zeneca Portugal, Medinfar Portugal.

João Conceição is an employee of MSD International GmbH (Singapore Branch).

João Pelicano-Romano is an employee of MSD Portugal.

Paula M de Jesus is an employee of MSD Portugal.

Estevão Pape, Mónica Reis, Árcia Chipepo, Edite Nascimento, Ana Baptista, Vanessa Pires, Carlos Marques, Adriana De Sousa Lages have no conflict of interests.

\section{Author details}

${ }^{1}$ MSD Portugal, R. Qta da Fonte 19, 2770-192 Paço de Arcos, Portugal. ${ }^{2}$ MSD International GmbH (Singapore Branch), Medical Affairs, Singapore, Singapore. ${ }^{3}$ Centro Hospitalar e Universitário do Porto, Porto, Portugal. ${ }^{4}$ Centro Hospitalar e Universitário de Coimbra, Coimbra, Portugal. ${ }^{5}$ Faculdade de Medicina da Universidade de Coimbra, Coimbra, Portugal. ${ }^{6}$ Beatriz Ângelo Hospital, Loures, Portugal. ${ }^{7}$ Hospital Garcia de Orta, Almada, Portugal. ${ }^{8}$ Hospital de Vila Franca de Xira, Vila Franca de Xira, Portugal. ${ }^{9}$ Centro Hospitalar Tondela Viseu, Viseu, Portugal. ${ }^{10}$ Centro Hospitalar Universitário do Algarve - Faro, Faro, Portugal. ${ }^{11}$ Centro Hospitalar de Trás-os-Montes e Alto Douro, Vila Real, Portugal. ${ }^{12}$ Unidade Local de Saúde do Baixo Alentejo, Beja, Portugal.

Received: 8 July 2020 Accepted: 27 November 2020

Published online: 05 January 2021

\section{References}

1. American Diabetes Association. Classification and diagnosis of diabetes: standards of medical care in diabetes - 2020. Diabetes Care. 2020; 43(Suppl 1):S14-31.

2. World Health Organization. Diabetes: fact sheet. 2018. Available from: https://www.who.int/news-room/fact-sheets/detail/diabetes.
3. Sociedade Portuguesa de Diabetologia. Diabetes: Factos e Números - O Ano de 2015 - Relatório Anual do Observatório Nacional da Diabetes 2016. Available from: www.spd.pt. Accessed Apr 2019.

4. Brackenridge A, Wallbank H, Lawrenson RA, Russell-Jones D. Emergency management of diabetes and hypoglycaemia. Emerg Med J. 2006;23(3):183-5.

5. Lipska KJ, Ross JS, Wang Y, Inzucchi SE, Minges K, Karter AJ, et al. National trends in US hospital admissions for hyperglycemia and hypoglycemia among Medicare beneficiaries, 1999 to 2011. JAMA Intern Med. 2014;174(7): 1116-24

6. Lind M, Pivodic A, Svensson A-M, Ólafsdóttir AF, Wedel H, Ludvigsson J. $\mathrm{HbA} 1 \mathrm{c}$ level as a risk factor for retinopathy and nephropathy in children and adults with type 1 diabetes: Swedish population based cohort study. BMJ. 2019:366:14894.

7. Inzucchi SE, Bergenstal RM, Buse JB, et al. Management of hyperglycemia in type 2 diabetes: a patient-centered approach - position statement of the American Diabetes Association (ADA) and the European Association for the Study of Diabetes (EASD). Diabetes Care. 2012;35:1364-79.

8. American Diabetes Association. Standards of medical care in diabetes 2019. Diabetes Care. 2019;42(Suppl. 1):S61-70.

9. Hulkower R, Pollack R, Zonszein J. Understanding hypoglycemia in hospitalized patients. Diabetes Manage. 2014:4(2):165-76.

10. Veronese G, Marchesini G, Forlani G, Saragoni S, Degli Esposti L, Centis E, et al. Costs associated with emergency care and hospitalization for severe hypoglycemia. Nutr Metab Cardiovasc Dis. 2016;26(4):345-51.

11. Veronese G, Marchesini G, Forlani G, Fabbri A, Italian Society of Emergency M. Are severe hypoglycemic episodes in diabetes correctly identified by administrative data? Evidence of underreporting from the HYPOTHESIS study. Acta Diabetol. 2016;53(4):677-80.

12. Sociedade Portuguesa de Diabetologia. Diabetes: Factos e Números - 0 Ano de 2010 - Relatório Anual do Observatório Nacional da Diabetes 2011. Available from: www.spd.pt. Accessed Apr 2019

13. Conceicao J, Dores J, Araujo F, Laires PA, Carr RD, Brodovicz K, et al. Severe hypoglycaemia among patients with type 2 diabetes requiring emergency hospital admission: the Hypoglycaemia In Portugal Observational StudyEmergency Room (HIPOS-ER). Diabetes Obes Metab. 2018;20(1):50-9.

14. Laires PA, Conceicao J, Araujo F, Dores J, Silva C, Radican L, et al. The cost of managing severe hypoglycemic episodes in type 2 diabetic patients. Expert Rev Pharmacoecon Outcomes Res. 2016;16(2):315-25.

15. American Diabetes Association. Defining and reporting hypoglycemia in diabetes. Diabetes Care. 2005;28(5):1245-9.

16. Seaquist ER, Anderson J, Childs B, Cryer P, Dagogo-Jack S, Fish L, et al. Hypoglycemia and diabetes: a report of a workgroup of the American Diabetes Association and the Endocrine Society. J Clin Endocrinol Metab. 2013;98(5):1845-59.

17. Kitabchi AE, Umpierrez GE, Miles JM, Fisher JN. Hyperglycemic crises in adult patients with diabetes. Diabetes Care. 2009;32(7):1335-43.

18. Xourgia E, Papazafiropoulou A, Karampousli E, Melidonis A. DPP-4 inhibitors vs. SGLT-2 inhibitors; cons and pros. J Renal Med. 2017;1(2):7.

19. Kalra S, Kesavadev J, Chadha M, Kumar GV. Sodium-glucose cotransporter-2 inhibitors in combination with other glucose-lowering agents for the treatment of type 2 diabetes mellitus. Indian J Endocrinol Metab. 2018;22(6): 827-36

20. Barnett A. Insulin glargine in the treatment of type 1 and type 2 diabetes. Vasc Health Risk Manag. 2006;2(1):59-67.

21. Davies MJ, D'Alessio DA, Fradkin J, Kernan WN, Mathieu C, Mingrone G, et al. Management of hyperglycemia in type 2 diabetes, 2018. A consensus report by the American Diabetes Association (ADA) and the European Association for the Study of Diabetes (EASD). Diabetes Care. 2018;41(12): 2669-701.

22. Morales J, Schneider D. Hypoglycemia. Am J Med. 2014;127(10 Suppl):S17-24.

23. Sociedade Portuguesa de Diabetologia. Recomendações nacionais da SPD para o tratamento da hiperglicemia na diabetes tipo 2 - atualização 2018/ 19 com base na posição conjunta ADA/EASD. Revista Portuguesa de Diabetes. 2018;13(4):154-80.

24. Torre C, Guerreiro JP, Romano S, Miranda A, Longo P, Alao S, et al. Realworld prevalence of mild to moderate hypoglycemic episodes in type 2 diabetes in Portugal: results from the HIPOS-PHARMA study. Prim Care Diabetes. 2018:12(6):537-46.

25. Ferreira JP, Araujo F, Dores J, Santos L, Pape E, Reis M, et al. Hospitalization 605 costs due to hypoglycemia in patients with diabetes: a microcosting approach. Diabetes Ther. 2020;11(10):2237-55. 
26. Inkster B, Zammitt NN, Frier B. Drug-induced hypoglycaemia in type 2 diabetes. Expert Opin Drug Saf. 2012;11:597-614.

27. Esteves C, Neves C, Carvalho D. A Hipoglicemia no Diabético. Revista Portuguesa de Diabetes. 2013;8:161-7.

28. Teixeira S, Giestas A, Amaral C, Dores J. Análise dos episódios de hipoglicemia ocorridos em diabéticos no serviço de urgência do Centro Hospitalar do Porto. Revista Portuguesa de Diabetes. 2008;3(1 Suppl):29-32.

29. Biesenbach G, Raml A, Schmekal B, Eichbauer-Sturm G. Decreased insulin requirement in relation to GFR in nephropathic type 1 and insulin-treated type 2 diabetic patients. Diabet Med. 2003;20:642-5.

30. Snyder RW, Berns JS. Use of insulin and oral hypoglycemic medications in patients with diabetes mellitus and advanced kidney disease. Semin Dial. 2004;17(5):365-70.

31. Horton ES, Johnson C, Lebovitz HE. Carbohydrate metabolism in uremia. Ann Intern Med. 1968;68:63-76.

32. Moen MF, Zhan M, Hsu VD, Walker LD, Einhorn LM, Seliger SL, et al. Frequency of hypoglycemia and its significance in chronic kidney disease. Clin J Am Soc Nephrol. 2009;4(6):1121-7.

33. Bloomfield HE, Greer N, Newman D, et al. Predictors and consequences of severe hypoglycaemia in adults with diabetes - a systematic review of the evidence. VA-ESP Project \#09-009; 2012.

34. Seaquist ER, Anderson J, Childs B, Cryer P, Dagogo-Jack S, Fish L, et al. Hypoglycemia and diabetes: a report of a workgroup of the American Diabetes Association and the Endocrine Society. Diabetes Care. 2013;36(5): 1384-95.

35. Ahren B. Avoiding hypoglycemia: a key to success for glucose-lowering therapy in type 2 diabetes. Vasc Health Risk Manag. 2013;9:155-63.

36. Wang J, Geiss LS, Williams DE, Gregg EW. Trends in emergency department visit rates for hypoglycemia and hyperglycemic crisis among adults with diabetes, United States, 2006-2011. PLoS One. 2015;10(8):e0134917.

37. Prajapati VB, Blake R, Acharya LD, Seshadri S. Assessment of quality of life in type II diabetic patients using the modified diabetes quality of life (MDQoL)-17 questionnaire. Braz J Pharm Sci. 2018;53(4):e17144.

38. Giorda CB, Rossi MC, Ozzello O, Gentile S, Aglialoro A, Chiambretti A, et al. Healthcare resource use, direct and indirect costs of hypoglycemia in type 1 and type 2 diabetes, and nationwide projections. Results of the HYPOS-1 study. Nutr Metab Cardiovasc Dis. 2017;27(3):209-16.

39. Mazzi S, Ravasio R, Forlani G, Veronese G, Fabbri A, Marchesini G. Estimating the risk of severe hypoglycemic event related to glucose-lowering treatment among Italian patients with diabetes: the HYPOTHESIS database. Clinicoecon Outcomes Res. 2017:9:711-20.

40. International Diabetes Federation. IDF global guideline for managing older people with type 2 diabetes. 2013. Available from: www.idf.org.

41. Marchesini G, Veronese G, Forlani G, Forlani G, Ricciardi LM, Fabbri A, et al. The management of severe hypoglycemia by the emergency system: the HYPOTHESIS study. Nutr Metab Cardiovasc Dis. 2014;24(11):1181-8.

42. Salutini E, Bianchi C, Santini M, Dardano A, Daniele G, Penno G, et al. Access to emergency room for hypoglycaemia in people with diabetes. Diabetes Metab Res Rev. 2015;31(7):745-51.

43. Edridge $\mathrm{CL}$, Dunkley AJ, Bodicoat DH, Rose TC, Gray LJ, Davies MJ, et al. Prevalence and incidence of hypoglycaemia in 532,542 people with type 2 diabetes on oral therapies and insulin: a systematic review and metaanalysis of population based studies. PLoS One. 2015;10(6):e0126427.

44. Elwen FR, Huskinson A, Clapham L, Bottomley MJ, Heller SR, James C, et al. An observational study of patient characteristics and mortality following hypoglycemia in the community. BMJ Open Diabetes Res Care. 2015;3(1): e000094.

45. Manisha S, Parulekar, et al. Polypharmacy. Geriatr Rehabil. 2018. https://doi. org/10.1016/B978-0-323-54454-2.00009-1.

46. Varghese D, Haseer KH. Polypharmacy. [Updated 2020 Feb 18]. In: StatPearls [Internet]. Treasure Island (FL): StatPearls Publishing; 2020. PMID: 30422548.

47. Rowe BH, Singh M, Villa-Roel C, Leiter LA, Hramiak I, Edmonds ML, et al. Acute management and outcomes of patients with diabetes mellitus presenting to Canadian emergency departments with hypoglycemia. Can J Diabetes. 2015;39(1):55-64.

\section{Publisher's Note}

Springer Nature remains neutral with regard to jurisdictional claims in published maps and institutional affiliations.

\section{Ready to submit your research? Choose BMC and benefit from:}

- fast, convenient online submission

- thorough peer review by experienced researchers in your field

- rapid publication on acceptance

- support for research data, including large and complex data types

- gold Open Access which fosters wider collaboration and increased citations

- maximum visibility for your research: over $100 \mathrm{M}$ website views per year

At BMC, research is always in progress.

Learn more biomedcentral.com/submissions 